\title{
Development and validation of a clinical model (DREAM-LDL) for post- stroke cognitive impairment at 6 months
}

\author{
Yi Dong ${ }^{1}$, Mengyuan Ding ${ }^{1}$, Mei Cui ${ }^{1}$, Min Fang ${ }^{2}$, Li Gong ${ }^{2}$, Zhuojun X ${ }^{3}$, Yue Zhang ${ }^{3}$, \\ Xiuzhe Wang ${ }^{4}$, Xiaofeng $\mathrm{Xu}^{4}$, Xueyuan $\mathrm{Liu}^{2}$, Gang Li ${ }^{3}$, Yuwu Zhao ${ }^{4}$, Qiang Dong ${ }^{1}$ \\ ${ }^{1}$ Department of Neurology, Huashan Hospital, State Key Laboratory of Medical Neurobiology and MOE Frontiers \\ Center for Brain Science, Fudan University, Shanghai, China \\ 2Department of Neurology, The Tenth People's Hospital Affiliated to Tongji University, Shanghai, China \\ ${ }^{3}$ Department of Neurology, The East Hospital Affiliated to Tongji University, Shanghai, China \\ ${ }^{4}$ Department of Neurology, The Six People's Hospital Affiliated to Shanghai Jiao Tong University, Shanghai, China
}

Correspondence to: Qiang Dong; email: dong_qiang@fudan.edu.cn

Keywords: post-stroke cognitive impairment, acute ischemic stroke, the Montreal cognitive assessment, risk factors, low-density lipoprotein cholesterol

Received: March 23, 2021

Accepted: August 17, 2021

Published: September 10, 2021

Copyright: (C) 2021 Dong et al. This is an open access article distributed under the terms of the Creative Commons Attribution License (CC BY 3.0), which permits unrestricted use, distribution, and reproduction in any medium, provided the original author and source are credited.

\section{ABSTRACT}

Introduction: This multicenter, retrospective study assessed the prevalence of post-stroke cognitive impairment (PSCI) 6 months after acute ischemic stroke (AIS) and its risk factors to build a bedside early predictive model for PSCl using the Montreal Cognitive Assessment (MoCA).

Methods: Records of consecutive patients with AIS treated at 4 stroke centers in Shanghai had MoCA assessments within 2 weeks after AIS onset and 6 months later were reviewed. Prevalence of PSCl (MoCA<22) was calculated and risk factors were identified by multivariate logistic regression analysis. The modeling and validation and identified risk factors were included in a predictive model using multivariate regression.

Results: There were 383 patients included and prevalence of PSCI 6 months after AIS was 34.2\%, significantly lower than prevalence of patients with acute cognitive impairment (49.6\%). Aging, less education, higher glucose level and severe stroke were PSCI risk factors, while level of low-density lipoprotein cholesterol (LDL-C) had a paradox effect on the risk of $\mathrm{PSCl}$. $40.0 \%$ of the patients with cognitive impairment at acute phase reverted to normal, and patients with LDL-C 1.8-2.5 mmol/L were more likely to revert. The predictive model we built, DREAM-LDL (Diabetes [fasting blood glucose level], Rating [NIHSS], level of Education, Age, baseline MoCA and LDL-C level), had an AUROC of 0.93 for predicting $\mathrm{PSCl}$ at 6 months.

Conclusion: PSCI was common among AIS patients 6 months after AIS. We provided a practical tool to predict $\mathrm{PSCl}$ based on MoCA and risk factors present during acute phase of AIS.

\section{INTRODUCTION}

Cognitive impairment is common in adults after stroke, which might increase the disability and mortality in post-stroke patient as well $[1,2]$. Poststroke cognitive impairment (PSCI) refers to cognitive impairment that develops after a stroke without any indications of major pre-stroke cognitive decline [3]. Prevalence of PSCI varies among different reports, ranging from $20 \%$ to $82 \%$ [3-6]. Because PSCI might recover due to rehabilitation and neuroplasticity during the first few months after stroke [3, 7], while less improvement would be found after 6 months [8, 9]. Therefore, it is essential to identify stroke survivors with high risk of developing PSCI as early as possible, so that early preventive and treatment measures could be taken to prevent or delay PSCI [1-3]. 
As a screening tool, the Montreal Cognitive Assessment (MoCA) is sensitive in detecting early PSCI. Though it was reported that MoCA score was a good predictor of PSCI in 6-9 month after stroke $[4,10]$, some risk factors such as age, level of education, medical history of hypertension, diabetes mellitus, smoking and atrial fibrillation reported, were associated with higher risk of PSCI $[3,11,12]$. However, the role of MoCA results in acute phase or any other bedside tool for PSCI risk is still lacking.

The aim of this study was to identify factors associated with 6-month PSCI. Using the characteristics and features in the acute stage of AIS, to build an easy and practical predictive model for PSCI in Chinese population would be helpful in identifying high-risk patients as early as the acute phase of AIS. In addition, there was of interest to explore the potential subgroup of patients with cognitive impairment at acute phase who returned to normal cognitive performance ("reverters") 6 months after AIS onset.

\section{MATERIALS AND METHODS}

\section{Study design and patients}

This study was a multicenter retrospective study, which was approved by the Huashan Hospital Institutional Review Board (IRB protocol number V2.0; ethical approval number KY2017-201) and of each participating center before the study began. The trial was conducted in accordance with the guiding principles of the Declaration of Helsinki. All patients or their caregivers gave written informed consent before data collection.

The records of consecutive patients with confirmed AIS treated at 4 regional stroke centers from June 2017 to February 2018 were retrospectively reviewed. AIS was diagnosed by a neurologist according to the World Health Organization definition. Patients with AIS were provided with a MoCA assessment both within 2 weeks after AIS onset (baseline MoCA) and 6 months after AIS (6-month MoCA) [13]. Patients with pre-existing cognitive impairment before AIS according to their medical records and patients with severe cognitive impairment or aphasia who might be unable to undertake MoCA assessment were excluded. Then those patients' medical records were further extracted including their demographic, baseline characteristics and clinical information such as the National Institutes of Health Stroke Scale (NIHSS) score [8, 10, 12], the subtype of stroke classification $[8,12]$ and the Oxfordshire Community Stroke Project (OCSP) classification were also collected [14].

\section{Outcome measures}

A patient with a baseline MoCA score $<22$ was considered to have acute cognitive impairment, and a patient with a 6-month MoCA score <22 was diagnosed as PSCI [10]. An additional point was added to a patient's MoCA total score when his/her education was less than 12 years [10]. The scores of the $7 \mathrm{MoCA}$ subdomains (visuospatial/executive, naming, attention, language, abstraction, delayed recall and orientation) [13] were also recorded, separately. Additionally, the changes of patients' 6-month MoCA scores were assessed for all patients [13].

The number and percentage of patients with acute cognitive impairment who recovered and had normal cognitive performance 6 month after AIS (MoCA $\geq 22$ ) ("reverters") were calculated and factors associated with the reverters were determined.

\section{Statistical analysis}

Categorical data was described with number (n) and percentage $(\%)$ while normally distributed continuous data was described with mean \pm standard deviation (SD) and non-normally distributed continuous data was described with median (interquartile range [IQR]). Prevalence of acute cognitive impairment and 6-month PSCI were calculated with the number of patients with cognitive impairment as numerator and the number of all included patients as denominator, and $95 \%$ confidential interval (CI) was estimated with Poisson distribution. Comparisons between two groups were performed using the chi-square test or Fisher's exact test for categorical data, the Student t test for normally distributed continuous data and the Mann-Whitney U test or Wilcoxon rank sum tests (when appropriate) for non-normally distributed continuous data. Factors associated with PSCI were studied using univariate analysis entering patients' baseline demographic and clinical characteristics. We put most variables with $\mathrm{p}<0.1$ into the multivariate logistic regression and interactions would be tested before. The results were presented as odds ratios (ORs) with 95\%CI. Statistical analyses were performed using the Stata V15.1(College Station, TX, USA). All tests were two-tailed, and a $P$ value $<0.05$ was considered statistically significant.

\section{Modeling and validation}

The risk factors associated with PSCI at 6 months identified by the multivariate analysis were included in multivariate logistic regression analysis based on data from patients from 2 of the 4 centers (Huashan Hospital and the Tenth People's Hospital) to build a 
predictive model for predicting a patient's risk of developing PSCI 6 months after AIS. A scoring system (point 1-3) was used to score each risk factor in the model based on their OR and 95\% CI. The model's discriminatory ability was assessed with receiver operating characteristic (ROC) analysis using the area under the curve (AUC), and the HosmerLemeshow test was used to confirm that the observed event rates match expected event rates in subgroups of the modeling population and to assess calibration of the model. Internal cross-validation of the regression model between parameters of the DREAM-LDL Scale score and 6-month cognitive impairment was based on 1,000 bootstrap replicates. Estimated mean accuracy and $95 \%$ confidence intervals would be analyzed. External validation of our predictive model was done in a separate cohort, another 2 of the 4 hospitals (East Hospital and Sixth People's Hospital).

\section{RESULTS}

\section{Prevalence of PSCI 6 months after AIS and its risk factors}

The study flow diagram was illustrated in Figure 1 total of 383 AIS patients were included in this study. They had a median age of 63 (interquartile range [IQR]: 56-70) years, and $75.46 \%$ of them were male. Most of them had mild or moderate stroke (NIHSS $\leq 15,88.77 \%$ ).
Of the 383 patients, 131 patients had PSCI 6 months after their AIS onset and the prevalence of PSCI is $34.2 \%$ (95\%CI 29.5\%-39.1\%). Demographics and baseline characteristics of the PSCI and non-PSCI patients at 6 months were described in Table 1 . Univariate analysis revealed that compared to the non-PSCI population, the PSCI population had higher percentage of patients who were elder, female and more severe stroke and with fewer years of education. The PSCI population also had a significantly different distribution of patients with LDL- C level $<1.8 \mathrm{mmol} / \mathrm{L}, \quad 1.8-2.5 \mathrm{mmol} / \mathrm{L}$ and $\geq 2.6 \mathrm{mmol} / \mathrm{L}$ (Supplementary Figure 1).

Multivariate logistic regression analysis were listed in Supplementary Table 1 and only MoCA performance was independently related to the risk of PSCI at 6 months (Table 2).

Spearman's rank correlation indicated that a patient's baseline MoCA score was negatively correlated to the risk of PSCI at 6-month ( $\mathrm{rs}=-0.61, \mathrm{P}<0.001)$.

\section{Temporal changes of the patients' cognitive performance}

According to these patients' baseline MoCA assessments taken within 2 weeks of their AIS onset, 190 of the 383 patients had acute cognitive impairment (49.6\%), the prevalence of acute phase was significantly higher than the prevalence of PSCI 6 months after AIS

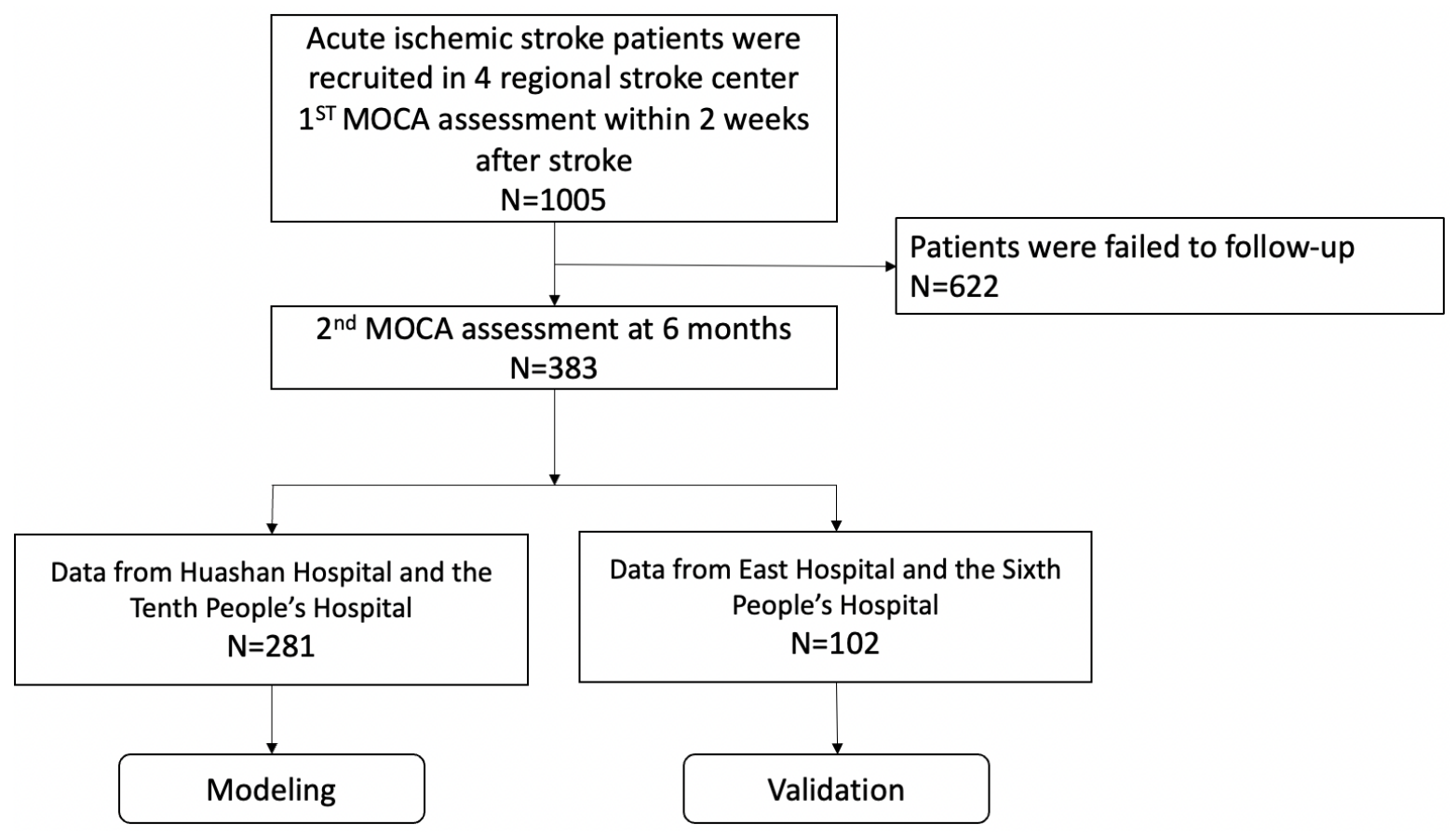

Figure 1. Study flowchart. 
Table 1. Patient demographic and baseline characteristics.

\begin{tabular}{|c|c|c|c|c|}
\hline Variables & All patients $(\mathrm{N}=383)$ & Non-PSCI (N=252) & PSCI (N=131) & $P$ value* \\
\hline Age, years, median (IQR) & $63.00(56.00-70.00)$ & $62.00(56.00-69.50)$ & $64.00(56.00-71.00)$ & 0.063 \\
\hline $63<$ Age $<80, \mathrm{n}(\%)$ & $93(24.28)$ & $58(21.64)$ & $35(30.43)$ & 0.140 \\
\hline Male, n (\%) & $289(75.46)$ & $211(78.73)$ & $78(67.83)$ & $0.023^{*}$ \\
\hline BMI, kg/m², median (IQR) & & $24.22(22.49-26.45)$ & $23.48(21.54-25.39)$ & 0.058 \\
\hline Level of education & & & & $0.002 *$ \\
\hline$>5$ and $\leq 9$ years, $\mathrm{n}(\%)$ & $140(36.55)$ & $95(35.45)$ & $45(39.13)$ & \\
\hline$>9$ and $\leq 12$ years, $n(\%)$ & $116(30.29)$ & $91(33.96)$ & $25(21.74)$ & \\
\hline$>12$ years, $\mathrm{n}(\%)$ & $64(16.71)$ & $49(18.28)$ & $15(13.04)$ & \\
\hline Severity of stroke, median[interquartile] & $11[2-14]$ & $11[2-14]$ & $11[3-14]$ & $0.016^{*}$ \\
\hline Mild-Moderate (NIHSS $\leq 8), \mathrm{n}(\%)$ & $199(51.96)$ & $137(51.11)$ & $62(65.35)$ & 0.985 \\
\hline Large artery atherosclerosis, $\mathrm{n}(\%)$ & $241(63.09)$ & $174(64.93)$ & $67(58.77)$ & \\
\hline Cardioembolism, n (\%) & $22(5.76)$ & $15(5.60)$ & $7(6.14)$ & \\
\hline Small vessel occlusion, $\mathrm{n}(\%)$ & $88(23.04)$ & $61(22.76)$ & $27(23.68)$ & \\
\hline Other cause, n (\%) & $11(2.88)$ & $9(3.36)$ & $2(1.75)$ & \\
\hline Unknown cause, $\mathrm{n}(\%)$ & $20(5.24)$ & $9(3.36)$ & $11(9.65)$ & \\
\hline OCSP classification & & & & 0.112 \\
\hline TACI, $\mathrm{n}(\%)$ & $12(3.14)$ & $5(1.87)$ & $7(6.14)$ & \\
\hline PACI, n (\%) & $218(56.62)$ & $152(56.72)$ & $66(57.89)$ & \\
\hline POCI, n (\%) & $21(5.50)$ & $17(6.34)$ & $4(3.51)$ & \\
\hline LACI, n (\%) & $131(34.39)$ & $94(35.07)$ & $37(32.46)$ & \\
\hline$\geq 2.6, \mathrm{n}(\%)$ & $194(51.19)$ & $137(51.70)$ & $57(50.00)$ & \\
\hline \multicolumn{5}{|l|}{ Medical history } \\
\hline Hypertension, n (\%) & $185(48.30)$ & $134(50.00)$ & $51(44.35)$ & 0.310 \\
\hline Diabetes, n (\%) & $102(26.63)$ & $66(24.63)$ & $36(31.30)$ & 0.175 \\
\hline Dyslipidemia, n (\%) & $7(1.83)$ & $5(1.87)$ & $2(1.74)$ & 0.320 \\
\hline Atrial fibrillation, n (\%) & $16(0.41)$ & $8(0.32)$ & $8(0.61)$ & 0.175 \\
\hline Prior stroke, n (\%) & $8(2.09)$ & $8(2.99)$ & $0(0.00)$ & 0.055 \\
\hline Myocardial infarction, $\mathrm{n}(\%)$ & $2(0.052)$ & $2(0.75)$ & $0(0.00)$ & 0.489 \\
\hline
\end{tabular}

* $P$ value referred to comparison between $\mathrm{PSCl}$ and non-PSCl patients.

$\mathrm{PSCl}$, post-stroke cognitive impairment; IQR, interquartile range; FBG, fasting blood glucose; LDL-C, low density lipoprotein (LDL) cholesterol; NIHSS, The National Institutes of Health Stroke Scale; TOAST, Trial of ORG 10172 in Acute Stroke Treatment; OCSP, The Oxfordshire Community Stroke Project; TACl, total anterior circulation infarct; PACl, partial anterior circulation infarct; $\mathrm{POCl}$, posterior circulation infarct; $\mathrm{LACl}$, lacunar circulation infarct.

(34.2\%). Of the 190 patients with acute/subacute cognitive impairment, $76(40.0 \%)$ patients recovered (reverter) and had normal cognitive status 6 month after AIS, while $17(8.9 \%)$ with normal cognitive status at baseline deteriorated and had PSCI 6 month after AIS.
The patients' general and domain-specific changes in their cognitive performance were described in Table 3. Among them, the mean MoCA score of patients with PSCI at 6 months $(\mathrm{N}=131)$ had insignificant improvement from baseline $(15.78 \pm 5.60$ at baseline vs 
Table 2. Multivariate logistic regression analysis of risk/protective factors for patients developing PSCI 6 month after acute ischemic stroke.

\begin{tabular}{|c|c|c|c|}
\hline Variables & OR & $95 \% \mathrm{CI}$ & P value \\
\hline Baseline MoCA & 0.74 & $0.69 \sim 0.78$ & $<0.001$ \\
\hline \multicolumn{3}{|c|}{ Level of education ( $<6 \mathrm{yr}$ as reference, as categorical variables) } & 0.219 \\
\hline $6-9$ years & 1.15 & $0.50 \sim 2.63$ & \\
\hline $9-12$ years & 0.72 & $0.30 \sim 1.71$ & \\
\hline$\geq 12$ years & 0.70 & $0.27 \sim 1.89$ & \\
\hline \multicolumn{3}{|l|}{ Age(as categorical variables) } & 0.572 \\
\hline$\leq 63$ years old & As refer & & \\
\hline $63<$ Age $<80$ years old & 1.30 & $0.73 \sim 2.32$ & \\
\hline$\geq 80$ years old & 0.94 & $0.29 \sim 3.03$ & \\
\hline \multicolumn{4}{|l|}{ FBG (as categorical variables) } \\
\hline$\leq 5.4 \mathrm{mmol} / \mathrm{L}$ & As refer & & 0.482 \\
\hline $5.4 \mathrm{mmol} / \mathrm{L}<\mathrm{FBG}<7.1 \mathrm{mmol} / \mathrm{L}$ & 1.49 & $0.76 \sim 2.95$ & \\
\hline$\geq 7.1 \mathrm{mmol} / \mathrm{L}$ & 1.27 & $0.64 \sim 2.53$ & \\
\hline \multicolumn{3}{|c|}{ LDLC level (LDL-C $<1.8 \mathrm{mmol} / \mathrm{L}$ or $\mathrm{LDL}-\mathrm{C} \geq 2.6 \mathrm{mmol} / \mathrm{L}$ as reference) } & 0.327 \\
\hline $0.3342 .6>\mathrm{LDL}-\mathrm{C} \geq 1.8 \mathrm{mmol} / \mathrm{L}$ & 0.76 & $0.43 \sim 1.33$ & \\
\hline \multicolumn{3}{|c|}{ Severity of Stroke (NIHSS, points, as categorical variables) } & 0.876 \\
\hline Moderate $(8<$ NIHSS $<15), \mathrm{n}(\%)$ & 1.11 & $0.57 \sim 2.14$ & \\
\hline Severe (NIHSS $\geq 15), \mathrm{n}(\%)$ & 0.90 & $0.43 \sim 1.89$ & \\
\hline
\end{tabular}

PSCI, post-stroke cognitive impairment; OR, odd ratio; Cl, confidential interval; LDL-C, low density lipoprotein (LDL) cholesterol.

Table 3. Temporal changes of MoCA total and subdomain scores in patients with acute ischemic stroke.

\begin{tabular}{|c|c|c|c|c|c|c|c|c|c|c|c|c|}
\hline \multirow[b]{2}{*}{ Domains } & \multirow{2}{*}{$\begin{array}{c}\text { Scoring } \\
\text { range }\end{array}$} & \multicolumn{3}{|c|}{ All patients $(\mathrm{N}=383)$} & \multicolumn{3}{|c|}{ PSCI (N=131) } & \multicolumn{3}{|c|}{ Non-PSCI $(\mathrm{N}=252)$} & \multirow[b]{2}{*}{ t-test values } & \multirow[b]{2}{*}{ P value } \\
\hline & & Baseline & 6-month & $\begin{array}{c}t \text {-test } \\
\text { values }\end{array}$ & Baseline & 6-month & $\begin{array}{c}\text { t-test } \\
\text { values }\end{array}$ & Baseline & 6-month & t-test values & & \\
\hline $\begin{array}{l}\text { Visuospatial/ } \\
\text { executive }\end{array}$ & $0-5$ & $2.91 \pm 1.64$ & $3.39 \pm 1.48$ & 6.21 & $1.81 \pm 1.43$ & $2.16 \pm 1.47$ & 2.31 & $3.48 \pm 1.44$ & $4.02 \pm 1.01$ & 6.30 & 14.54 & $<0.001$ \\
\hline Naming & $0-3$ & $2.54 \pm 0.80$ & $2.44 \pm 0.80$ & -2.37 & $2.10 \pm 1.00$ & $1.90 \pm 1.01$ & -2.20 & $2.76 \pm 0.55$ & $2.72 \pm 0.49$ & -1.07 & 10.91 & $<0.001$ \\
\hline Attention & $0-6$ & $4.91 \pm 1.37$ & $5.02 \pm 1.27$ & 1.66 & $4.02 \pm 1.62$ & $4.07 \pm 1.51$ & 0.37 & $5.37 \pm 0.96$ & $5.52 \pm 0.74$ & 2.01 & 12.46 & $<0.001$ \\
\hline Language & $0-3$ & $1.97 \pm 1.07$ & $1.96 \pm 1.01$ & -0.24 & $1.26 \pm 1.02$ & $1.07 \pm 0.92$ & -1.85 & $2.35 \pm 0.88$ & $2.42 \pm 0.69$ & 1.19 & 16.04 & $<0.001$ \\
\hline Abstraction & $0-2$ & $1.15 \pm 0.79$ & $1.46 \pm 0.91$ & 6.09 & $0.72 \pm 0.73$ & $0.79 \pm 0.75$ & 1.00 & $1.37 \pm 0.72$ & $1.81 \pm 0.79$ & 1.00 & 12.06 & $<0.001$ \\
\hline Delayed recall & $0-5$ & $1.95 \pm 1.71$ & $2.91 \pm 1.74$ & 10.52 & $0.92 \pm 1.44$ & $1.31 \pm 1.48$ & 2.58 & $2.49 \pm 1.60$ & $3.75 \pm 1.19$ & 11.36 & 17.55 & $<0.001$ \\
\hline Orientation & $0-6$ & $5.29 \pm 1.29$ & $5.43 \pm 1.17$ & 2.07 & $4.70 \pm 1.63$ & $4.67 \pm 1.67$ & -0.21 & $5.6 \pm 0.93$ & $5.82 \pm 0.43$ & 3.57 & 10.30 & $<0.001$ \\
\hline Total & $0-30$ & $21.55 \pm 5.99$ & $23.44 \pm 5.69$ & 9.20 & $16.41 \pm 5.72$ & $16.85 \pm 4.54$ & 1.11 & $24.23 \pm 4.07$ & $26.87 \pm 2.01$ & 11.84 & 29.83 & $<0.001$ \\
\hline
\end{tabular}

The $t$ tests were performed to compare the baseline performance to the 6 -month performance in all patients, PCSI population and non-PSCl population, respectively.

${ }^{\mathrm{t}} \mathrm{t}$ tests were also performed between PCSI population and non-PSC population at 6 months.

* $P$ value referred to comparison between $\mathrm{PSCl}$ and non-PSCl patients at 6 months.

Variables were expressed as mean \pm standard deviation (SD).

MoCA, the Montreal Cognitive Assessment.

$16.13 \pm 4.40$ at 6 months, $P=0.0519$ ), while there was significant improvement in the 252 non-PSCI patients' mean MoCA score $(24.03 \pm 4.17$ at baseline vs $26.58 \pm 2.27$ at 6 months, $P<0.001$ ). For patients with PSCI, their visuospatial/executive and delayed recall improved significantly, naming and language abilities deteriorated while their attention, abstraction and orientation remained stable. Overall, non-PSCI patients performed significantly better than PSCI patients in all of the 7 subdomains of MoCA and also MoCA total scores at baseline as well as 6 months after their AIS (All $\mathrm{P}<0.001$ ).

In addition, 76 the 190 patients (40.0\%) with cognitive impairment at acute phase recovered and reverted back to have normal cognitive status at 6month after AIS. The reverters' mean MoCA score improve to $25.71 \pm 1.89$ at 6 -month from the baseline 
$19.34 \pm 3.23(\mathrm{P}<0.001)$. Multivariate logistic regression in patients with acute cognitive impairment revealed that patient with appropriate LDL level was more likely to be reverters (OR 1.79, 95\%CI: 1.00 3.22, $\mathrm{P}=0.041$ ).

\section{Predictive model building and validation}

The internal validation model was based on 281 patients from Huashan Hospital and the Tenth People's Hospital. The predictive model, DREAMLDL, included 6 variables: diabetes (fasting blood glucose level), rating (severity of stroke as reflected by NIHSS at admission), level of education, age, baseline MoCA and LDL-C level. DREAM-LDL had a risk score ranging from 0 to 10 (Table 4). We scored these risk factors according to their odds ratio (Supplementary Tables 1,2). The DREAM-LDL had an AUROC of 0.93, its Hosmer-Lemeshow $\operatorname{chi}^{2}(8)$ was 1.49 (Figure 2A). Accuracy of the derivation model based on 1,000 bootstrap replicates was $75.7 \%$ $(66.4 \%-84.9 \%)$. A 3-tier scoring system was used to evaluate a patient's risk of having PSCI 6 months after AIS. A patient with a score of $0-2$ points was considered to have low risk, a patient with a score of 3-5 points was considered to have a moderate risk and a patient with 6 points or high was considered to have a high risk.

External validation of the model was performed on the 102 patients from the 2 of the 4 hospitals in the study (East Hospital and the Sixth People's Hospital). 7.89\% of the patients with a score of $0-2$ points, $40.68 \%$ of the patients with a score of $3-5$ points and $78.82 \%$ of the patients with a score of 6 points or higher had PSCI 6 months after AIS (Figure 2B). The higher the DREAMLDL score was, the higher the likelihood of PSCI at 6month. There was no statistical difference in AUC-ROC between the derivation and validation cohorts. Additionally, we compared the performance of DREAM-LDL in reverters and non-reverters in Supplementary Figure 2, which showed no statistical difference.

\section{DISCUSSION}

Our finding of PSCI prevalence of $34.2 \%$ was consistent with the mid-term PSCI prevalence reported by these previous studies $[1,4,6,15]$. Based on this AIS database, we found PSCI was common at 6-months and that old age, fewer year of education, history of atrial fibrillation and acute cognitive impairment were risk factors for PSCI. However, the LDL-C level of $1.8-2.5 \mathrm{mmol} / \mathrm{L}$ was a likely protective factor against PSCI. We established and validated a bedside predictive tool, DREAM-LDL, which could be helpful in early detection of PSCI and potential reverters.

Our study showed that LDL-C played a paradox role in whether a patient was at risk of PSCI 6 months after AIS (Supplementary Figure 1). Previous studies produced conflicting results on relationship between LDL-C level and cognitive ability [16-32]. According to the National Lipid Association recommendations for patient-centered management of dyslipidemia, the desirable LDL-C level was $<1.8 \mathrm{mmol} / \mathrm{L}(100 \mathrm{mg} / \mathrm{dL})$ for people at very high risk of atherosclerotic cardiovascular disease (ASCVD) and $<2.6 \mathrm{mmol} / \mathrm{L}(130 \mathrm{mg} / \mathrm{dL})$ for those without clinical evidence of ASCVD or other very high-risk conditions [33]. Our result indicated that LDL-C in the upper range of normal is most suitable for reducing the risk of PSCI as well as increasing the likelihood of patients with acute cognitive impairment to recover.

Therefore, our DREAM-LDL bedside tool might be helpful to identify AIS patients at risk of mid- and longterm PSCI as early as possible. Most variables included in our DREAM-LDL risk score were identified by previous studies as important risk factors for PSCI [3, 11-13, 34-39]. Several current available predictive tools input some neuroimaging and techniques $[3,12$, $38,39]$. The $\mathrm{SIGNAL}_{2}$ risk score consists of age stages, education $<6$ years, global cortical atrophy stages, Fazekas stages, non-lacunar cortical infarct stages, chronic lacunes $\geq 2$ and intracranial stenosis [12]. The CHANGE risk score includes age, education, cortical atrophy, acute cortical non-lacunar infarcts, white matter hyperintensities (WMH) and chronic lacunes [3]. The GRECogVASC cognitive risk score consists of NIHSS $\geq 7$ at admission $(\geq 7)$, multiple strokes, adjusted MMSE $\leq 27$, and Fazekas score $\geq 2$ [37]. Finally, Ding et al. developed a PSCI risk model consisting of age, years of education, periventricular hyperintensity grading, diabetes mellitus and the number of acute nonlacunar infarcts as variables [36]. Neuroimaging information is needed for all of these 4 models [3, 12, $36,37]$. Our risk score does not rely on any neuroimaging information, therefore, is simple and easy to administer in intensive stroke unit. Of course, the model needs to be tested and further validated in other AIS patient populations.

Our study has certain limitations. First, it was a 6-month study, therefore how these patients' cognitive performance would evolve beyond 6 months could not be evaluated. Secondly, only very few of the included patients (11.23\%) suffered severe stroke and as such, the effect of severity of stroke on the risk of PSCI and patients' likelihood to recover could not be adequately evaluated. However, it was the nature or limit of a retrospective study. Thirdly, we used a MoCA cutoff 
Table 4. DREAM-LDL: a clinical model for the risk of PSCl at 6-month.

\begin{tabular}{ll}
\hline Risk factors & Scores \\
\hline Diabetes(FBG, $\mathbf{~ m m o l} / \mathbf{L})$ & 2 \\
FBG $>7.1$ & 1 \\
$7.1>$ FBG $>5.4$ & \\
Rating(Severity of Stroke, NIHSS) & 2 \\
NIHSS $\geq 15$ & 1 \\
$15 \geq$ NIHSS $\geq 8$ & \\
Level of Education & 2 \\
No more than 9 years & 1 \\
No more than 12 years & \\
Age & 2 \\
$>80$ years old & 1 \\
$>$ 63 years old & 2 \\
Baseline MoCA $<2$ & 1 \\
Inappropriate LDL-C $(\mathbf{1 . 8}-\mathbf{2 . 6 m m o l} / \mathbf{L})$ & \\
\hline
\end{tabular}

DREAM LDL scale predict PSCl after stroke is ranged from 0-10 points. Low risk is as $0-2$ points. Moderate risk is as 3-5 points. High risk is defined as 6 or higher.

FBG, Fasting blood glucose; NIHSS, The National Institutes of Health Stroke Scale; LDL-C, low density lipoprotein (LDL) cholesterol; MoCA, Montreal Cognitive Assessment.

value of 22 in the current study for estimating prevalence of PSCI and for building the predicting model for PSCI. which was lower than mean MoCA score of old healthy subjects reported by many studies
[40-45]. Fourthly, the MoCA testing was originally designed for detecting mild cognitive impairment, but not for PSCI and therefore it does not include assessment of some of the cognitive deficits commonly

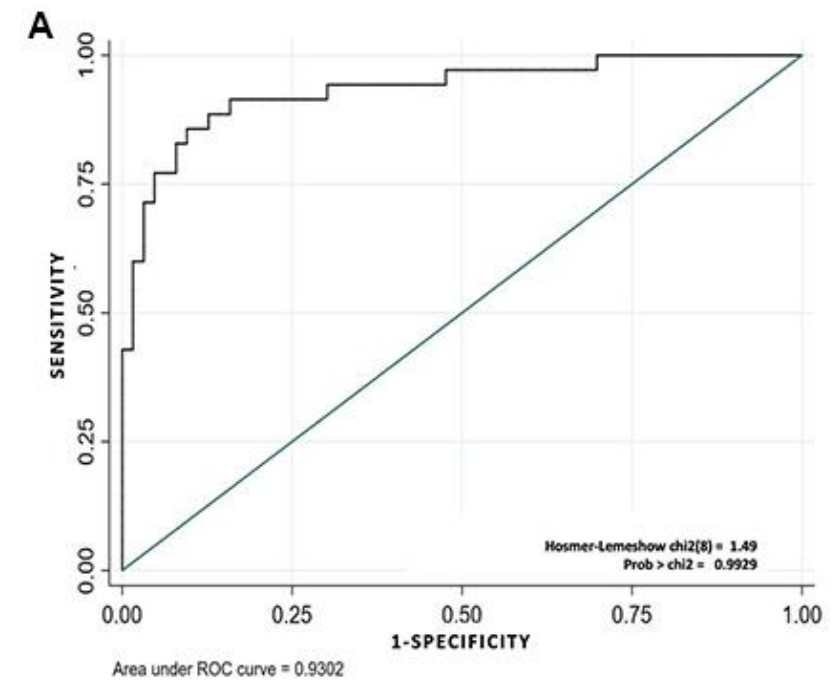

- Receiver operating characteristic curves was performed based on 281 patients cohort, for prediction of PSCl at 6 month follow-up in AIS patients within 2 weeks.

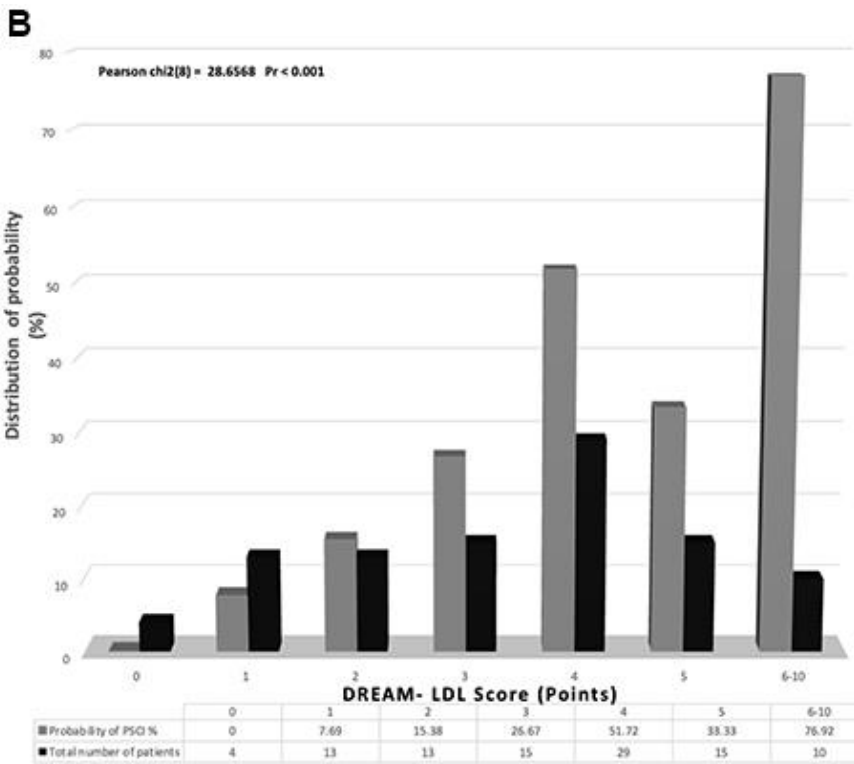

Figure 2. The establishment and validation of the DREAM-LDL scale. (A) Receiver operating characteristic (ROC) curve based on a cohort of 281 patients for identifying AIS patients at risk of mid-term PSCl as early as within 2 weeks of AIS onset. (B) The DREAM-LDL scale was validated in another cohort of 102 AIS patients. 
seen after stroke such as aphasia, neglect, visual loss, apraxia and reading/writing problems [46-48]. However, up till now, the MoCA test is still the commonly used bedside screening tool for PSCI. Therefore, it should be assumed that AIS patients with severe stroke symptoms incapable of completing the MoCA testing were at high risk of developing PSCI.

In conclusion, PSCI was common among AIS survivor 6 months after AIS. Our finding provided a tool for early identification of AIS patients at high risk of developing PSCI.

\section{Abbreviations}

AIS: acute ischemic stroke; LDLC: low-density lipoprotein cholesterol; PSCI: Post-stroke cognitive impairment; IRB: Institutional Review Board; MoCA: Montreal Cognitive Assessment; NIHSS: National Institutes of Health Stroke Scale; OCSP: Oxfordshire Community Stroke Project; CI: confidential interval; DREAM-LDL: Diabetes [fasting blood glucose level], Rating [NIHSS], level of Education, Age, baseline MoCA and LDL-C level; IQR: interquartile range; ASCVD: atherosclerotic cardiovascular disease; FBG: fasting blood glucose level; OR: odd ratio; SD: standard deviation.

\section{AUTHOR CONTRIBUTIONS}

Y.D. performed data analysis, drafted the manuscript. M.Y.D., M.C., M.F., L.G., Z.J.X, Y.Z., X.Z.W. and X.F.X participated in patient assessment, data collection. Y.D., X.Y.L., Y.W.Z. and G.L participated in the study design and revised the manuscript. Q.D. was in charge of the study conception, supervised the analysis and finalized the manuscript. All authors have reviewed and approved the submitted version and have agreed both to be personally accountable for the author's own contributions and to ensure that questions related to the accuracy or integrity of any part of the work, even ones in which the author was not personally involved, are appropriately investigated, resolved, and the resolution documented in the literature.

\section{CONFLICTS OF INTEREST}

The funder had no role in study design, data collection and analysis, or writing of this study. There were no other conflicts of interests.

\section{FUNDING}

This study was funded by Eisai China Inc.

\section{REFERENCES}

1. Qu Y, Zhuo L, Li N, Hu Y, Chen W, Zhou Y, Wang J, Tao $Q$, Hu J, Nie X, Zhan S. Prevalence of post-stroke cognitive impairment in China: a community-based, cross-sectional study. PLoS One. 2015; 10:e0122864. https://doi.org/10.1371/journal.pone.0122864 PMID:25874998

2. Tang EY, Amiesimaka O, Harrison SL, Green E, Price C, Robinson L, Siervo M, Stephan BC. Longitudinal Effect of Stroke on Cognition: A Systematic Review. J Am Heart Assoc. 2018; 7:e006443. https://doi.org/10.1161/JAHA.117.006443 PMID:29335318

3. Chander RJ, Lam BY, Lin X, Ng AY, Wong AP, Mok VC, Kandiah N. Development and validation of a risk score (CHANGE) for cognitive impairment after ischemic stroke. Sci Rep. 2017; 7:12441.

https://doi.org/10.1038/s41598-017-12755-z PMID:28963553

4. Chaurasia RN, Sharma J, Pathak A, Mishra VN, Joshi D. Poststroke Cognitive Decline: A Longitudinal Study from a Tertiary Care Center. J Neurosci Rural Pract. 2019; 10:459-64.

https://doi.org/10.1055/s-0039-1697872

PMID:31595118

5. Zhou DH, Wang JY, Li J, Deng J, Gao C, Chen M. Frequency and risk factors of vascular cognitive impairment three months after ischemic stroke in China: the Chongqing stroke study. Neuroepidemiology. 2005; 24:87-95. https://doi.org/10.1159/000081055 PMID:15459515

6. Tu Q, Ding B, Yang X, Bai S, Tu J, Liu X, Wang R, Tao J, Jin $H$, Wang $Y$, Tang $X$. The current situation on vascular cognitive impairment after ischemic stroke in Changsha. Arch Gerontol Geriatr. 2014; 58:236-47. https://doi.org/10.1016/j.archger.2013.09.006 PMID:24148887

7. Lim JS, Oh MS, Lee JH, Jung S, Kim C, Jang MU, Lee $\mathrm{SH}$, Kim YJ, Kim Y, Park J, Kang Y, Yu KH, Lee BC. Prediction of post-stroke dementia using NINDS-CSN 5-minute neuropsychology protocol in acute stroke. Int Psychogeriatr. 2017; 29:777-84. https://doi.org/10.1017/S1041610216002520 PMID:28120733

8. Turunen KE, Laari SP, Kauranen TV, Uimonen J, Mustanoja S, Tatlisumak T, Poutiainen E. DomainSpecific Cognitive Recovery after First-Ever Stroke: A 2-Year Follow-Up. J Int Neuropsychol Soc. 2018; 24:117-27. https://doi.org/10.1017/S1355617717000728 PMID:28791943 
9. Rasquin SM, Lodder J, Verhey FR. Predictors of reversible mild cognitive impairment after stroke: a 2year follow-up study. J Neurol Sci. 2005; 229:21-25. https://doi.org/10.1016/i.jns.2004.11.015 PMID:15760615

10. Salvadori E, Pasi M, Poggesi A, Chiti G, Inzitari D, Pantoni L. Predictive value of MoCA in the acute phase of stroke on the diagnosis of mid-term cognitive impairment. J Neurol. 2013; 260:2220-27.

https://doi.org/10.1007/s00415-013-6962-7 PMID:23716072

11. Sun JH, Tan L, Yu JT. Post-stroke cognitive impairment: epidemiology, mechanisms and management. Ann Transl Med. 2014; 2:80.

https://doi.org/10.3978/i.issn.2305-5839.2014.08.05 PMID:25333055

12. Kandiah N, Chander RJ, Lin X, Ng A, Poh YY, Cheong CY, Cenina AR, Assam PN. Cognitive Impairment after Mild Stroke: Development and Validation of the SIGNAL2 Risk Score. J Alzheimers Dis. 2016; 49:1169-77. https://doi.org/10.3233/JAD-150736 PMID:26599056

13. Nijsse B, Visser-Meily JM, van Mierlo ML, Post MW, de Kort PL, van Heugten CM. Temporal Evolution of Poststroke Cognitive Impairment Using the Montreal Cognitive Assessment. Stroke. 2017; 48:98-104. https://doi.org/10.1161/STROKEAHA.116.014168 PMID:27899753

14. De Silva DA, Woon FP, Pin LM, Chen CP, Chang HM, Wong MC. Intracranial large artery disease among OCSP subtypes in ethnic South Asian ischemic stroke patients. J Neurol Sci. 2007; 260:147-49.

https://doi.org/10.1016/i.jns.2007.04.020 PMID:17524424

15. Zhang $Y$, Zhang Z, Yang B, Li Y, Zhang Q, Qu Q, Wang Y, Zhang S, Yue W, Tan Y, Zhang B, Xu T. Incidence and risk factors of cognitive impairment 3 months after first-ever stroke: a cross-sectional study of 5 geographic areas of China. J Huazhong Univ Sci Technolog Med Sci. 2012; 32:906-11. https://doi.org/10.1007/s11596-012-1056-9 PMID:23271295

16. Williamson JB, Nyenhuis DL, Pedelty L, Byrd S, Jhaveri M, Wang C, deToledo-Morrell L, Sripathirathan K, Gorelick P. Baseline differences between vascular cognitive impairment no dementia reverters and nonreverters. J Neurol Neurosurg Psychiatry. 2008; 79:1208-14.

https://doi.org/10.1136/innp.2007.137554

PMID:18477711

17. Yoon JA, Kim DY, Sohn MK, Lee J, Lee SG, Lee YS, Han EY, Joo MC, Oh GJ, Han J, Park M, Park KP, Noh KH, et al. Factors associated with improvement or decline in cognitive function after an ischemic stroke in Korea: the Korean stroke cohort for functioning and rehabilitation (KOSCO) study. BMC Neurol. 2017; 17:9. https://doi.org/10.1186/s12883-016-0780-3 PMID:28073355

18. He Q, Li Q, Zhao J, Wu T, Ji L, Huang G, Ma F. Relationship between plasma lipids and mild cognitive impairment in the elderly Chinese: a case-control study. Lipids Health Dis. 2016; 15:146.

https://doi.org/10.1186/s12944-016-0320-6 PMID:27595570

19. Kálmán J, Kudchodkar BJ, Murray K, McConathy WJ, Juhász A, Janka Z, Lacko AG. Evaluation of serum-lipidrelated cardiovascular risk factors in Alzheimer's disease. Dement Geriatr Cogn Disord. 1999; 10:488-93. https://doi.org/10.1159/000017195 PMID:10559565

20. Liu Y, Zhong X, Shen J, Jiao L, Tong J, Zhao W, Du K, Gong S, Liu M, Wei M. Elevated serum TC and LDL-C levels in Alzheimer's disease and mild cognitive impairment: A meta-analysis study. Brain Res. 2020; 1727:146554.

https://doi.org/10.1016/j.brainres.2019.146554 PMID:31765631

21. Lv YB, Yin ZX, Chei CL, Brasher MS, Zhang J, Kraus VB, Qian F, Shi XM, Matchar DB, Zeng Y. Serum Cholesterol Levels within the High Normal Range Are Associated with Better Cognitive Performance among Chinese Elderly. J Nutr Health Aging. 2016; 20:280-87. https://doi.org/10.1007/s12603-016-0701-6 PMID:26892577

22. Moroney JT, Tang MX, Berglund L, Small S, Merchant C, Bell K, Stern Y, Mayeux R. Low-density lipoprotein cholesterol and the risk of dementia with stroke. JAMA. 1999; 282:254-60.

https://doi.org/10.1001/jama.282.3.254 PMID:10422994

23. Reitz C, Tang MX, Luchsinger J, Mayeux R. Relation of plasma lipids to Alzheimer disease and vascular dementia. Arch Neurol. 2004; 61:705-14. https://doi.org/10.1001/archneur.61.5.705 PMID:15148148

24. Reitz C, Tang MX, Manly J, Schupf N, Mayeux R, Luchsinger JA. Plasma lipid levels in the elderly are not associated with the risk of mild cognitive impairment. Dement Geriatr Cogn Disord. 2008; 25:232-37. https://doi.org/10.1159/000115847 PMID:18264008

25. Romero-Sevilla R, Casado-Naranjo I, Portilla-Cuenca JC, Duque-de San Juan B, Fuentes JM, Lopez-Espuela F. Vascular Risk Factors and Lesions of Vascular Nature in Magnetic Resonance as Predictors of Progression to Dementia in Patients with Mild Cognitive Impairment. Curr Alzheimer Res. 2018; 15:671-78. 
https://doi.org/10.2174/156720501566618011910084 o PMID:29357793

26. Sparks DL, Kryscio RJ, Connor DJ, Sabbagh MN, Sparks LM, Lin Y, Liebsack C. Cholesterol and cognitive performance in normal controls and the influence of elective statin use after conversion to mild cognitive impairment: results in a clinical trial cohort. Neurodegener Dis. 2010; 7:183-86.

https://doi.org/10.1159/000295660 PMID:20224282

27. West R, Beeri MS, Schmeidler J, Hannigan CM, Angelo G, Grossman HT, Rosendorff C, Silverman JM. Better memory functioning associated with higher total and low-density lipoprotein cholesterol levels in very elderly subjects without the apolipoprotein e4 allele. Am J Geriatr Psychiatry. 2008; 16:781-85.

https://doi.org/10.1097/JGP.0b013e3181812790 PMID:18757771

28. Yin ZX, Shi XM, Kraus VB, Fitzgerald SM, Qian HZ, Xu JW, Zhai Y, Sereny MD, Zeng Y. High normal plasma triglycerides are associated with preserved cognitive function in Chinese oldest-old. Age Ageing. 2012; 41:600-06.

https://doi.org/10.1093/ageing/afs033

PMID:22447910

29. Zhou F, Deng W, Ding D, Zhao Q, Liang X, Wang F, Luo J, Zheng L, Guo Q, Hong Z. High Low-Density Lipoprotein Cholesterol Inversely Relates to Dementia in Community-Dwelling Older Adults: The Shanghai Aging Study. Front Neurol. 2018; 9:952.

https://doi.org/10.3389/fneur.2018.00952

PMID:30483213

30. Zou Y, Zhu Q, Deng Y, Duan J, Pan L, Tu Q, Dai R, Zhang $X$, Chu LW, Lü Y. Vascular risk factors and mild cognitive impairment in the elderly population in Southwest China. Am J Alzheimers Dis Other Demen. 2014; 29:242-47.

https://doi.org/10.1177/1533317513517042

PMID:24375574

31. Presećki P, Mück-Seler D, Mimica N, Pivac N, Mustapić M, Stipcević T, Smalc VF. Serum lipid levels in patients with Alzheimer's disease. Coll Antropol. 2011 (Suppl 1); 35:115-20.

PMID:21648320

32. Lo JW, Crawford JD, Desmond DW, Godefroy O, Jokinen $\mathrm{H}$, Mahinrad S, Bae HJ, Lim JS, Köhler S, Douven E, Staals J, Chen C, Xu X, et al, and Stroke and Cognition (STROKOG) Collaboration. Profile of and risk factors for poststroke cognitive impairment in diverse ethnoregional groups. Neurology. 2019; 93:e2257-71. https://doi.org/10.1212/WNL.0000000000008612 PMID:31712368
33. Jacobson $T A$, Ito $M K$, Maki KC, Orringer $C E$, Bays $H E$, Jones PH, McKenney JM, Grundy SM, Gill EA, Wild RA, Wilson DP, Brown WV. National lipid association recommendations for patient-centered management of dyslipidemia: part 1--full report. J Clin Lipidol. 2015; 9:129-69.

https://doi.org/10.1016/j.jacl.2015.02.003

PMID:25911072

34. Jacquin A, Binquet $C$, Rouaud $O$, Graule-Petot $A$, Daubail B, Osseby GV, Bonithon-Kopp C, Giroud M, Béjot Y. Post-stroke cognitive impairment: high prevalence and determining factors in a cohort of mild stroke. J Alzheimers Dis. 2014; 40:1029-38. https://doi.org/10.3233/JAD-131580 PMID:24577459

35. Zietemann V, Georgakis MK, Dondaine T, Müller C, Mendyk AM, Kopczak A, Hénon $H$, Bombois $S$, Wollenweber FA, Bordet R, Dichgans M. Early MoCA predicts long-term cognitive and functional outcome and mortality after stroke. Neurology. 2018; 91:e1838-50.

https://doi.org/10.1212/WNL.0000000000006506 PMID:30333158

36. Ding MY, Xu Y, Wang YZ, Li PX, Mao YT, Yu JT, Cui M, Dong $Q$. Predictors of Cognitive Impairment After Stroke: A Prospective Stroke Cohort Study. J Alzheimers Dis. 2019; 71:1139-51.

https://doi.org/10.3233/JAD-190382 PMID:31524163

37. Godefroy $\mathrm{O}$, Yaïche H, Taillia H, Bompaire F, NédélecCiceri C, Bonnin C, Varvat J, Vincent-Grangette F, Diouf M, Mas JL, Canaple S, Lamy C, Arnoux A, et al, and GRECogVASC Study Group. Who should undergo a comprehensive cognitive assessment after a stroke? A cognitive risk score. Neurology. 2018; 91:e1979-87. https://doi.org/10.1212/WNL.0000000000006544 PMID:30333160

38. Chaudhari TS, Verma R, Garg RK, Singh MK, Malhotra HS, Sharma PK. Clinico-radiological predictors of vascular cognitive impairment (VCl) in patients with stroke: a prospective observational study. J Neurol Sci. 2014; 340:150-58.

https://doi.org/10.1016/j.jns.2014.03.018 PMID:24680559

39. Kopecek M, Stepankova H, Lukavsky J, Ripova D, Nikolai T, Bezdicek O. Montreal cognitive assessment (MoCA): Normative data for old and very old Czech adults. Appl Neuropsychol Adult. 2017; 24:23-29. https://doi.org/10.1080/23279095.2015.1065261 PMID:27144665

40. Larouche E, Tremblay MP, Potvin O, Laforest S, Bergeron D, Laforce R, Monetta L, Boucher L, Tremblay P, Belleville S, Lorrain D, Gagnon JF, Gosselin N, et al. Normative Data for the Montreal Cognitive 
Assessment in Middle-Aged and Elderly Quebec-French People. Arch Clin Neuropsychol. 2016; 31:819-26.

https://doi.org/10.1093/arclin/acw076

PMID:27625048

41. Lu J, Li D, Li F, Zhou A, Wang F, Zuo X, Jia XF, Song H, Jia J. Montreal cognitive assessment in detecting cognitive impairment in Chinese elderly individuals: a population-based study. J Geriatr Psychiatry Neurol. 2011; 24:184-90.

https://doi.org/10.1177/0891988711422528

PMID:22228824

42. Malek-Ahmadi M, Powell JJ, Belden CM, O'Connor K, Evans L, Coon DW, Nieri W. Age- and educationadjusted normative data for the Montreal Cognitive Assessment (MoCA) in older adults age 70-99. Neuropsychol Dev Cogn B Aging Neuropsychol Cogn. 2015; 22:755-61.

https://doi.org/10.1080/13825585.2015.1041449

PMID:25942388

43. Mellor D, Lewis M, McCabe M, Byrne L, Wang T, Wang J, Zhu M, Cheng Y, Yang C, Dong S, Xiao S. Determining appropriate screening tools and cut-points for cognitive impairment in an elderly Chinese sample. Psychol Assess. 2016; 28:1345-53. https://doi.org/10.1037/pas0000271 PMID:26845223

44. Narazaki K, Nofuji Y, Honda T, Matsuo E, Yonemoto K, Kumagai S. Normative data for the montreal cognitive assessment in a Japanese community-dwelling older population. Neuroepidemiology. 2013; 40:23-29. https://doi.org/10.1159/000339753

PMID:23075757

45. Tan JP, Li N, Gao J, Wang LN, Zhao YM, Yu BC, Du W, Zhang WJ, Cui LQ, Wang QS, Li JJ, Yang JS, Yu JM, et al. Optimal cutoff scores for dementia and mild cognitive impairment of the Montreal Cognitive Assessment among elderly and oldest-old Chinese population. J Alzheimers Dis. 2015; 43:1403-12.

https://doi.org/10.3233/JAD-141278 PMID:25147113

46. Cameron JD, Gallagher R, Pressler SJ, McLennan SN, Ski CF, Tofler G, Thompson DR. Sensitivity and Specificity of a Five-Minute Cognitive Screening Test in Patients With Heart Failure. J Card Fail. 2016; 22:99-107. https://doi.org/10.1016/j.cardfail.2015.08.343 PMID:26386450

47. Demeyere N, Riddoch MJ, Slavkova ED, Jones K, Reckless I, Mathieson P, Humphreys GW. Domainspecific versus generalized cognitive screening in acute stroke. J Neurol. 2016; 263:306-15.

https://doi.org/10.1007/s00415-015-7964-4 PMID:26588918

48. Benaim C, Barnay JL, Wauquiez G, Bonnin-Koang HY, Anquetil C, Pérennou D, Piscicelli C, Lucas-Pineau B, Muja L, le Stunff E, de Boissezon X, Terracol C, Rousseaux $M$, et al. The Cognitive Assessment scale for Stroke Patients (CASP) vs. MMSE and MoCA in nonaphasic hemispheric stroke patients. Ann Phys Rehabil Med. 2015; 58:78-85. https://doi.org/10.1016/j.rehab.2014.12.001 PMID:25766087 


\section{SUPPLEMENTARY MATERIALS}

\section{Supplementary Figures}

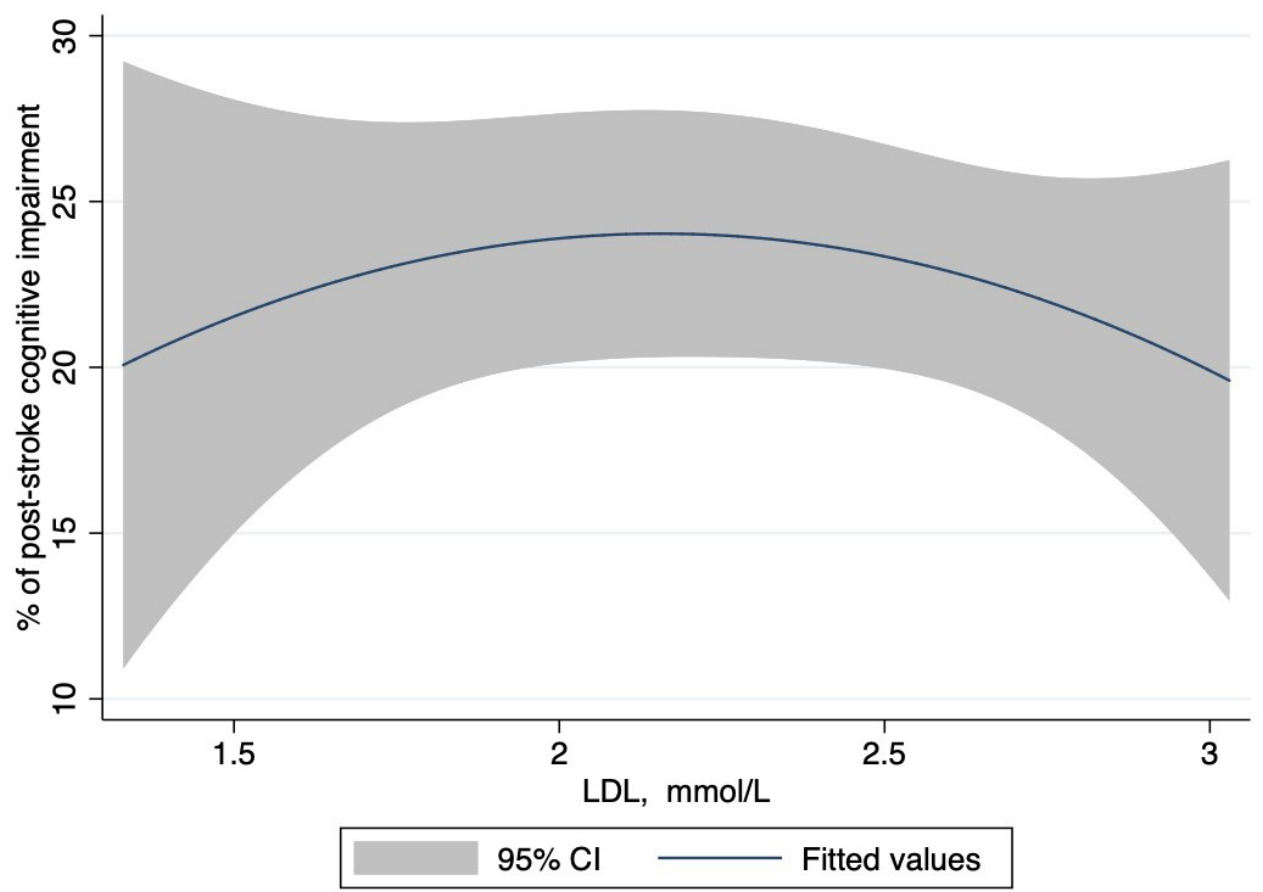

Supplementary Figure 1. The correlation between LDL level at baseline and risk of PSCI at 6 months after stroke.

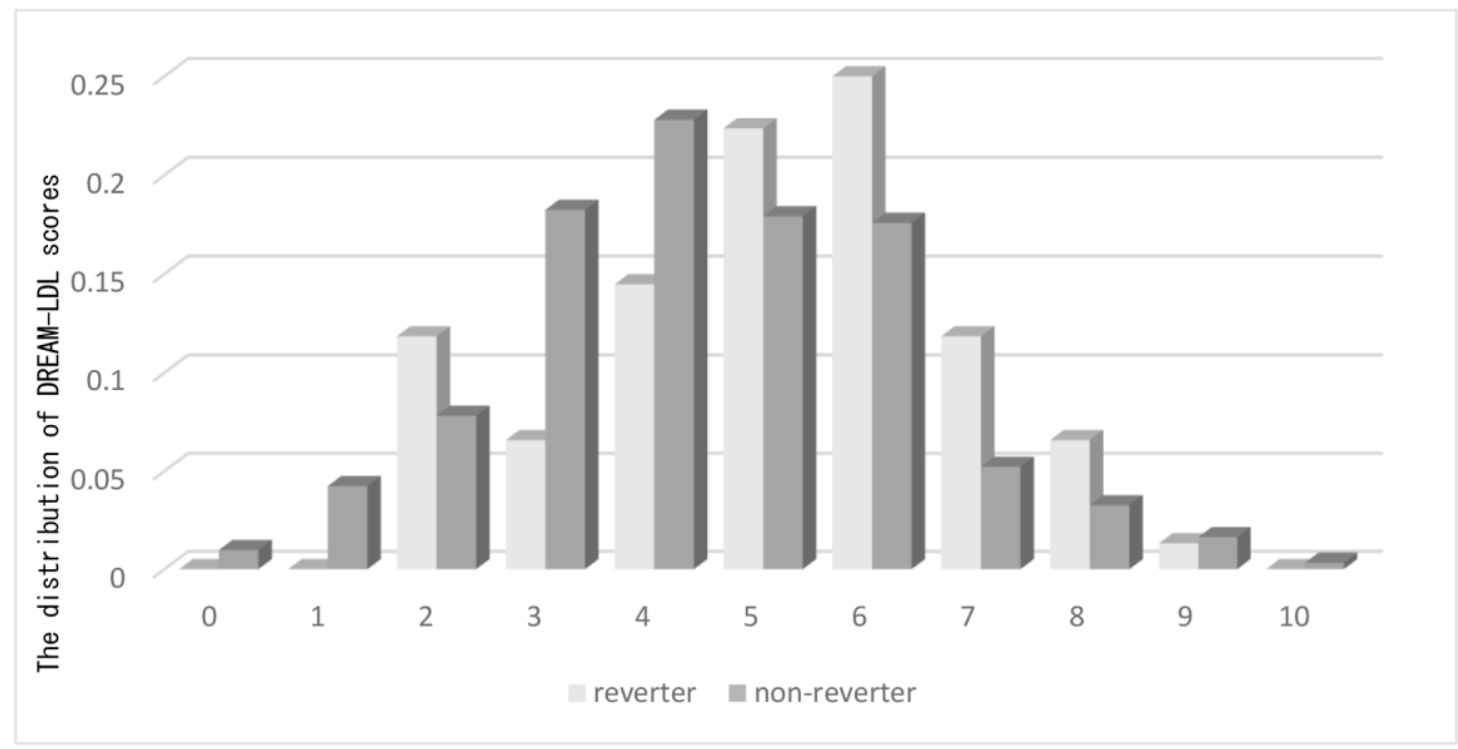

Supplementary Figure 2. Comparison of the distribution of DREAM-LDL scores between reverter and non-reverter. 


\section{Supplementary Tables}

Supplementary Table 1. The risk factors of PSCl at 6-month in logistic regression model.

\begin{tabular}{|c|c|c|c|c|c|c|}
\hline \multirow{3}{*}{$\begin{array}{l}\text { Variables } \\
\text { Age, each year }\end{array}$} & \multicolumn{3}{|c|}{ Univariable analysis } & \multicolumn{3}{|c|}{$\begin{array}{l}\text { Multivariable analysis, } \\
\text { as categorical variable }\end{array}$} \\
\hline & \multirow{2}{*}{$\begin{array}{c}\text { Odds ratio } \\
1.08\end{array}$} & \multicolumn{2}{|c|}{$95 \% \mathrm{CI}$} & \multirow{2}{*}{$\begin{array}{c}\text { Odds ratio } \\
1.15\end{array}$} & \multicolumn{2}{|c|}{$95 \% \mathrm{CI}$} \\
\hline & & 1.00 & 1.04 & & 0.66 & 2.02 \\
\hline$>63 \mathrm{yrs}$ & 1.38 & 0.91 & 2.12 & & & \\
\hline$>80 \mathrm{yrs}$ & 1.61 & 0.65 & 4.01 & & & \\
\hline $\begin{array}{l}\text { Level of education, } \\
\text { each } 3 \text { years }\end{array}$ & 0.69 & 0.54 & 0.86 & & & \\
\hline More than 9 years & 0.52 & 0.42 & 0.64 & 0.85 & 0.63 & 1.14 \\
\hline MoCA, each point & 0.63 & 0.56 & 0.70 & 0.74 & 0.69 & 0.78 \\
\hline Diabetes mellitus & 1.28 & 0.83 & 1.97 & & & \\
\hline Glucose level, $1 \mathrm{mmol}$ & 1.05 & 0.98 & 1.14 & 1.06 & 0.58 & 1.95 \\
\hline Glucose level $>5.4 \mathrm{mmol} / \mathrm{l}$ & 1.49 & 0.97 & 2.29 & & & \\
\hline Severity of Stroke & & & & 1.00 & 0.67 & 1.38 \\
\hline Baseline NIHSS score, 1 point & 1.04 & 1.00 & 1.08 & & & \\
\hline NIHSS $>8$ points & 1.65 & 1.04 & 2.63 & & & \\
\hline NIHSS $>15$ points & 1.29 & 0.98 & 1.70 & & & \\
\hline LDL level, 1 mmol/L & 1.02 & 0.96 & 1.09 & 0.76 & 0.43 & 1.33 \\
\hline Appropriate LDL(1.8-2.6mmol/L) & 0.69 & 0.45 & 1.05 & & & \\
\hline
\end{tabular}


Supplementary Table 2. Multivariate logistic regression analysis of the risk factors for PSCl at 6 months included in the predictive model for the patients from 2 of the 4 study centers (Huashan Hospital and the Tenth People's Hospital) ( $\mathrm{N}=\mathbf{2 8 1}$ ).

\begin{tabular}{|c|c|c|c|c|}
\hline \multirow{2}{*}{$\begin{array}{l}\text { Variables } \\
\text { Baseline MoCA }\end{array}$} & \multirow{2}{*}{$\begin{array}{c}\text { Odds ratio } \\
15.454\end{array}$} & \multicolumn{2}{|c|}{ 95\% Confidential interval } & \multirow{2}{*}{$\frac{\text { P value }}{0.000}$} \\
\hline & & 8.466 & -28.210 & \\
\hline \multicolumn{5}{|l|}{ Level of education } \\
\hline$<9$ years, $\mathrm{n}(\%)$ & 1.788 & 0.986 & -3.240 & 0.056 \\
\hline $9-11$ years & 1.825 & 0.908 & -3.667 & 0.091 \\
\hline$\geq 12$ years & As refer & & & \\
\hline \multicolumn{5}{|l|}{ Age } \\
\hline$\leq 63$ years old & As refer & & & \\
\hline 64-79 years old & 1.052 & 0.551 & -2.010 & 0.878 \\
\hline$\geq 80$ years old & 0.902 & 0.488 & -1.669 & 0.743 \\
\hline \multicolumn{5}{|l|}{ FBG } \\
\hline$\leq 5.4 \mathrm{mmol} / \mathrm{L}$ & As refer & & & \\
\hline $5.5-7.0 \mathrm{mmol} / \mathrm{L}$ & 1.572 & 0.834 & -2.963 & 0.162 \\
\hline$\geq 7.1 \mathrm{mmol} / \mathrm{L}$ & 1.191 & 0.641 & -2.213 & 0.581 \\
\hline \multicolumn{5}{|l|}{ LDL-C } \\
\hline $1.8-2.5 \mathrm{mmol} / \mathrm{L}$ & As refer & & & \\
\hline$<1.8 \mathrm{mmol} / \mathrm{L}$ or $\geq 2.6 \mathrm{mmol} / \mathrm{L}$ & 1.364 & 0.774 & --2.404 & 0.284 \\
\hline \multicolumn{5}{|l|}{ Severity of Stroke (NIHSS, points) } \\
\hline Moderate (NIHSS 9-14), n (\%) & 1.060 & 0.610 & -1.842 & 0.836 \\
\hline Severe (NIHSS $\geq 15), \mathrm{n}(\%)$ & 0.848 & 0.371 & --1.939 & 0.697 \\
\hline Atrial fibrillation & 1.172 & 0.638 & -2.154 & 0.638 \\
\hline
\end{tabular}

FBG, fasting blood glucose level; OR, odd ratio; Cl, confidential interval; LDL-C, low density lipoprotein (LDL) cholesterol; NIHSS, National Institution of Health Stroke Scale. 